\title{
On Ambitious Higher-Order Theories of Consciousness
}

\author{
Joseph Gottlieb \\ Texas Tech University \\ Forthcoming in Philosophical Psychology. Please cite published version.
}

\begin{abstract}
Ambitious Higher-Order theories of consciousness-Higher-Order theories that purport to give an account of phenomenal consciousness-face a well-known objection from the possibility of radical misrepresentation. Jonathan Farrell (2017) has recently added a new twist to an old worry: while Higher-Order theorists have the resources to respond to the misrepresentation objection, they do so at the expense of their ambitions. At best, they only account for phenomenal consciousness in the technical Higher-Order sense, not in the standard Nagelian sense. Building on the work of Berger (2014) and Brown (2015), I contend that Farrell's argument fails. The upshot is not only that radical misrepresentation presents no threat to the ambitiousness of Higher-Order theories, but also a deeper insight both into Higher-Order theories themselves, and what the standard Nagelian construal of phenomenal consciousness does, and does not, commit us to.
\end{abstract}

\section{Introduction}

Higher-Order (HO) theories of consciousness (e.g. Armstrong 1968; Lycan 1996; Rosenthal 2005; Kriegel 2009; Gennaro 2011; Brown 2015) are standardly introduced as implementations of the transitivity principle:

Transitivity A mental state $\mathrm{M}$ of a subject $\mathrm{S}$ is conscious only if $\mathrm{S}$ is in some way aware of $\mathrm{M} .^{1}$

To implement TRANSITIVITY is, in the main, to fill out it's 'in some way' clause. This gives us one way of individuating HO theories: HOT theories (e.g. Rosenthal 2005) differ from the HOP theories (e.g. Lycan 1996) because whereas the former says that $\mathrm{S}$ is aware of $\mathrm{M}$ via an assertoric higherorder thought (a HOT), the latter says that $S$ is aware of $M$ via a higher-order perception (a HOP).

Ned Block (2011) describes ambitious HO theorists as those that say TRANSITIVITY, or something near enough, can underpin an account of phenomenal consciousness, i.e. consciousness in the Nagelian (1974) what-it-is-like sense. David Rosenthal, Uriah Kriegel, and Richard Brown are

\footnotetext{
${ }^{1}$ This is the quick and dirty way of introducing $\mathrm{HO}$ theories. While many $\mathrm{HO}$ theorists do endorse TRANSITIVITY as stated, others do not. This point will be crucial as we proceed.
} 
ambitious by this measure. ${ }^{2}$ But some HO theorists, like David Armstrong, are less obviously ambitious. Their aims are modest. For them the HO-theoretic apparatus only targets some different form of consciousness (e.g. 'monitoring consciousness' or 'introspective consciousness'). My interest here is limited to ambitious $\mathrm{HO}$ theorists. So going forward 'HO theories' (and related expressions) should be understood as referring to ambitious HO theories.

$\mathrm{HO}$ theories face a well-known objection from the possibility of radical misrepresentation. ${ }^{3}$ In its strongest form, the objection centers on the ambitiousness of ambitious $\mathrm{HO}$ theories. The basic set-up goes like this. Let $M$ be a first-order state and let $M^{*}$ be a higher-order mental state. Suppose a subject $S$ instantiates $M^{*}$. Normally $M^{*}$ represents accurately. But here $M^{*}$ radically misrepresents: it represents a mental state $M$ that $S$ is not in. Yet $\mathrm{HO}$ theorists still want to say that $S$ is in a conscious state in such cases. ${ }^{4}$ If $S$ is in a conscious state (in the ambitious sense) then surely there must an occurrence of what-it-is-like-ness associated with that state. But which state? Not $M^{*}$ : this state is unconscious. $M^{*}$ is only conscious when $S$ introspects. It must therefore be $\mathrm{M}$-the state that $\mathrm{M}^{*}$ represents. But by stipulation $\mathrm{S}$ is not in $\mathrm{M}$. That's a problem, since $M$ and $M^{*}$ exhaust the options. ${ }^{5}$

Jonathan Farrell (2017) has argued that the way out of the misrepresentation objection turns on the $\mathrm{HO}$ theorist adopting a specific reading of two related notions, viz.:

SOMETHING There is something it is like for $\mathrm{S}$ to be in $\mathrm{M}$.

WHAT There is an occurrence of what-it-is-like-ness associated with M.

\footnotetext{
2 Perhaps for reasons stemming from his theory of mental qualities, Rosenthal does not seem fond of the expression 'phenomenal consciousness.' But this doesn't matter; Rosenthal is forthright that he is theorizing about consciousness as understood by Nagel's (1974) 'what it is like' locution. That's all I mean by 'phenomenal consciousness.'

${ }^{3}$ It is possible to construe TRANSITIVITY in non-representational terms, e.g. in terms of acquaintance (Hellie 2007), which would seem to immediately eliminate the possibility of radical misrepresentation. I am only concerned with representational forms of $\mathrm{HO}$ theory.

${ }^{4}$ It is tempting to think that the $\mathrm{HO}$ theorist should just say that there is no consciousness in such cases (e.g. Wilberg 2010) or perhaps construe the relationship between $M$ and $M^{*}$ as a constitutive one, such that radical misrepresentation is not possible (e.g. Kriegel 2009). The former move is not obviously plausible (Berger 2014), and it's not clear that the latter actually works (Weisberg 2008). Here I'll simply assume that misrepresentation is possible on a HO-theoretic account, and that in spite of such misrepresentation $S$ is still phenomenally conscious.

${ }^{5}$ The radical misrepresentation objection has a slight variant where the higher-order representation is not empty but involves failure of attribution-i.e. represents a mental state as having a property it does not have. My focus here is only on the radical case where there is no (first-order) mental state at all. So by 'misrepresentation objection' I mean 'radical misrepresentation objection.' Proponents of the misrepresentation objection in both forms include Byrne (1997), Neander (1998), and Levine (2001). Block (2011) - from whom Farrell takes inspiration-has provided a sharpening of the radical misrepresentation objection that he deems fatal in a way earlier versions were not.
} 
But this, Farrell contends, leads to a problem. The 'HO Reading'-the conjunction of the HO reading of SOMETHING and the HO reading of WHAT-is non-standard, and so different from what the proponents of the misrepresentation argument have in mind. As such, the HO theorist is changing the subject away from phenomenal consciousness. They are not responding to the misrepresentation argument as it is presented. So, at best, 'ambitious' HO theorists are not really ambitious: it is hard to see how HO theorists are doing anything but giving an account of whatit-is-likeness and phenomenal consciousness in just a technical HO sense.

I think Farrell is wrong: there is a way out for the $\mathrm{HO}$ theorist that does not require changing the subject. There is a form of $\mathrm{HO}$ theory that can respond to the misrepresentation argument while retaining its credentials as an ambitious $\mathrm{HO}$ theory.

The basic resources for such a $\mathrm{HO}$ theory already exist in the literature, especially in the work of Jacob Berger (2014) and Richard Brown (2015), but also some more recent work by David Rosenthal (2011). My aim is to (i) draw out these resources more forcefully in service of responding to Farrell's particular argument, and (ii) connect the resulting view to Nagelian 'what it is like'-talk. The upshot is that, at least insofar as the misrepresentation argument goes, there is no reason to see (all) HO theorists as adopting a specialized notion of such talk, and thus no reason to see (all) HO theorists as changing the subject. In addition, setting out these points will afford us a deeper insight into precisely what the standard Nagelian construal of phenomenal consciousness does, and does not, commit us to. ${ }^{6}$

Before we press on, two notes on the dialectic. First, a successful response to Farrell's challenge need not include a defense of this resultant HO theory, nor a full articulation of the theory. Farrell's claim is that the $\mathrm{HO}$ theorist can only 'respond' to the misrepresentation argument by changing the subject. My claim is that this is false. Establishing that only requires showing that the resultant $\mathrm{HO}$ theory is a genuine $\mathrm{HO}$ theory, and that we have not changed the subject. So that's where my focus will lie: articulating a theory that helps lay bare the scope of possibilities within the HO-theoretic framework, and getting clear on what is, and what is not, an account of phenomenal consciousness, neutrally understood. That said, I will suggest one way this type of $\mathrm{HO}$ theory could be filled out, laying down some details so as to sharpen both the similarities and differences with its predecessors, while also saying a few things in its favor. A full accounting of these issues, however, will be left aside here.

Second, it is tempting to think that there is a fairly straightforward response to Farrell: reject the Block-Nagel inspired modest-ambitious distinction as not only value-laden, but one on which it is

\footnotetext{
${ }^{6}$ Farrell also argues that the HO Reading (especially for SOMETHING) plays a crucial role in the awareness argument for $\mathrm{HO}$ theories. This argument aims to derive the truth of some form of $\mathrm{HO}$ theory from the fact that a mental state $M$ of a subject $S$ is conscious only if there is something it is like for $\mathrm{S}$ to be in $\mathrm{M}$. It has been claimed that at least some HO theorists do (if only tacitly) appeal to semantic considerations-considerations concerning what 'for $S$ ' means-in defense of this argument (Stoljar 2016, Gottlieb 2018), so Farrell might be right on this score. But whether Farrell is also right that the awareness argument fails on the HO reading, I leave open.
} 
virtually impossible for a $\mathrm{HO}$ theory to be ambitious while still being a $\mathrm{HO}$ theory. ${ }^{7}$ While I think this option has some merit, I sidestep it here. Instead, my aim is to grant the modest-ambitious distinction, and so how the misrepresentation argument has no force even within this BlockNagelian framework.

\section{The Problem}

Farrell's (p. 5) reconstruction of the misrepresentation objection runs like so:

M1 $M$ is conscious and $S$ is not in $M$.

M2 If $\mathrm{M}$ is conscious, there is something it is like for $\mathrm{S}$ to be in $\mathrm{M}$.

M3 If there is something it is like for $S$ to be in $M$, there is an occurrence of what-it-is-like ness associated with $\mathrm{M}$.

M4 If there is an occurrence of what-it-is-like-ness associated with $M, S$ is in $M$.

M5 If there is something it is like for $S$ to be in $M, S$ is in $M$.

M6 So, $\mathrm{S}$ is in $\mathrm{M}$.

$[\mathrm{M} 3, \mathrm{M} 4]$

$M 7$ So, $S$ is not in $M$.

M8 Therefore, $S$ is in $M$ and $S$ is not in $M$.

$[\mathrm{M} 6, \mathrm{M} 7]$

Clearly $\mathrm{M} 8$ is an unhappy result for the $\mathrm{HO}$ theorist. Farrell contends that the $\mathrm{HO}$ theorist must reject $\mathrm{M} 8$ by rejecting $\mathrm{M} 5$. This means that the $\mathrm{HO}$ theorist must reject $\mathrm{M} 3$ or $\mathrm{M} 4$.

Rejecting M3 might seem like the way to go for the simple reason that it appears to be false. This is because, according to Farrell (p. 6), the standard reading of SOMETHING is non-occurrent. It does not follow that if there is something it is like for $\mathrm{S}$ to be in $\mathrm{M}$ at $t$, that at $t$ there is an occurrence of what-it-is-like-ness associated with $\mathrm{M}$. There is something it is like for Mary to see red (or be in a visual state $M$ that represents red). That's true when Mary is in her black-and-white room. But when she is in her black-and-white room there is clearly no occurrence of what-it-is-like-ness. So all SOMETHING requires is that when $\mathrm{S}$ is in $\mathrm{M}$ (e.g., when Mary sees red), there is such an occurrence of what-it-is-like-ness, viz. that associated with seeing red.

However, Farrell (ibid) thinks that the $\mathrm{HO}$ theorist requires a non-standard, occurrent reading of SOMETHING, because HO theories are extrinsic theories of consciousness:

[O]n non-occurrent readings of SOMETHING, to say that there is something it is like for $\mathrm{S}$ to be in $\mathrm{M}$ is to say that when $\mathrm{S}$ is in $\mathrm{M}, \mathrm{S}$ undergoes phenomenology associated with $\mathrm{M}$. This cannot be true if what determines whether $S$ undergoes phenomenology associated with $M$

\footnotetext{
7 See Rosenthal (2011: 435) for something like this move in response to Block (2011), who first made the modest-ambitious distinction as applied to HO theories. But again, the extent to which Rosenthal is actually rejecting this distinction is unclear, given Rosenthal's assimilation of (what he calls) 'mental qualities' with phenomenal consciousness. In my view, Rosenthal's theory is a theory of phenomenal consciousness insofar as on his view $\mathrm{HO}$ representation generates what-it-is-likeness, and in that sense is ambitious (see fn. 2). In any event, I thank an anonymous referee for pointing out this option.
} 
depends, in part, on something other than $\mathrm{M}$ : $\mathrm{S}$ can be in $\mathrm{M}$ without the extra factor being present (ibid).

While I think Farrell's line is in a sense well-placed-some HO theorists do describe their theory as extrinsic (e.g. Weisberg 2011)-as we'll see in the next section, I think this commitment is wholly dispensable. But for now I propose we just grant Farrell's claim that rejecting M3 is not in the cards.

This leaves M4. Here Farrell distinguishes between tight and loose readings of WHAT. A tight reading entails the truth of $M 4$. This is what proponents of the misrepresentation argument have in mind. And, as Farrell points out, a tight reading is prima facie attractive. Farrell's example (ibid: 8 ) is pain. Suppose S stubs her toe. A mental state results. An occurrence of what-it-is-like-ness is associated with this state: throbbiness. The throbbiness contributes to what it is like overall to be $S$ at the time (or very after the time) she stubs her toe, but it also seems to imply that $S$ is in that state: what is being in pain if not there being certain types of what-it-is-like-ness (e.g. throbbiness) with which that state is associated (ibid)?

So, the $\mathrm{HO}$ theorist must adopt a loose reading, viz. one on which S doesn't need to be in M for there to be an occurrence of what-it-is-like-ness associated with M. Rosenthal (2011) does this by saying that sufficient for an occurrence of what-it-is-like-ness (e.g. throbbiness) is representing a state with certain (throbbing) qualities. That helps, the idea goes, since representing a state doesn't entail that the state that is represented exists.

Yet we are told that this victory is pyrrhic. It is pyrrhic due to the (ambitious) HO theorist's ambitions. Farrell's reasoning runs like this:

P1 To evade the misrepresentation argument, the $\mathrm{HO}$ theorist must reject M4.

P2 For the $\mathrm{HO}$ theorist to reject M4, the HO theorist must adopt the HO-Reading-in particular, she must adopt a loose reading of WHAT.

P3 HO theorists adopt a loose reading of WHAT.

P4 So, HO theorists evade the misrepresentation argument.

P5 But to adopt a loose reading of WHAT is to construe what-it-is-likeness and (phenomenal) consciousness contra to the way that it is normally understood-roughly, the Nagelian way.

P6 If the HO theorist construes what-it-is-likeness and (phenomenal) consciousness contra to the way that it is normally understood, then she is not an ambitious HO theorist.

P7 Thus, the HO theorist 'evades' the misrepresentation argument but only at the expense of realizing her ambitions.

[P4 - P6]

The full crux of the problem emerges in P7; even if there is nothing problematic about the HO reading itself, invoking it as a way of getting out of the misrepresentation argument is to change the subject. (Hence the scare quotes.) She will at best only have accounted for consciousness in the HO sense. That's bad. 


\section{The Solution}

Fortunately, there is another way out. The HO theorist should not reject M4,but M1:

M1 $M$ is conscious and $S$ is not in $M$.

In particular, I think the best move for the $\mathrm{HO}$ theorist is to reject the first conjunct of M1, viz. that the first-order state $M$ is conscious.

To say that $M$ is conscious is to say that $M$ is a conscious state. But when we talk of 'conscious states, ' there are, in general, two things we might mean. One is:

The InStANTIATION Model A conscious state is a mental state that instantiates the property of being conscious.

The literal reading of the predicate 'is conscious' in M1 suggest the Instantiation Model. But another option is:

THE TO-Be-IN MOdel

A conscious state is a mental state in virtue of which there is something it is like for (or to be) the subject of that state.

The To-Be-in Model is not incompatible with the Instantiation Model since it is possible that a mental state is a conscious state under the To-Be-In Model only if it instantiates the property of being conscious. The point though is that To-Be-in Model does not build this in. The expression 'conscious state' need not necessarily be understood as 'state that instantiates the property of being conscious.' So M1 might be understood as saying that it is in virtue of $M$ that there is something it is like for $\mathrm{S}$, despite $\mathrm{S}$ not being in $\mathrm{M}$-leaving aside whether $\mathrm{M}$ also instantiates the property of being conscious.

This means that M1's first conjunct-M is conscious - has two readings: one in accordance with The Instantiation Model, and one in accordance with The To-Be-In Model. Here is the proposal: on both readings, M1's first conjunct is false. $\mathrm{M} 1$ is false on The Instantiation Model reading because no mental state instantiates the property of being conscious. ${ }^{8} \mathrm{M} 1$ is false on The To-BeIn Model reading because the first-order state $M$ is not the state in virtue of which there is something it is like for $\mathrm{S}$, even when $\mathrm{S}$ is in $\mathrm{M}$.

Yet we can still say that there is consciousness in misrepresentation cases. For $\mathrm{M}^{*}$ - the higherorder mental state-is conscious on the To-Be-In Model: $\mathrm{S}$ is in $\mathrm{M}^{*}$, and it is in virtue of being in $M^{*}$ that there is something it is like for $S$. Like $M, M^{*}$ does not instantiate the property of being conscious. The only thing that instantiates the property of being conscious are subjects (cf. Berger 2014). The HO theorist should see herself as elucidating the nature of that property: S's being phenomenally conscious just is S instantiating the right kind of $\mathrm{M}^{*}$.

${ }^{8}$ Moreover, in the specific misrepresentation case here, $M$ does not even exist, and nonexistent things arguably cannot exhibit properties (cf. Mandik 2009). 
So that's the basic story. Two things are required at this juncture. First, we need to fill out the story. Specifically, we need to see how one can have $H O$ theory that rejects the idea that consciousness is a property of mental states, jettisons $\mathrm{M}$ from the consciousness-making picture (at least in the constitutive sense) and treats $\mathrm{M}^{*}$ as the conscious state. These core moves are not themselves terribly new, coming out most forcefully in the work of Berger (2014), but also in Brown (2015) and to some extent, Rosenthal (2011). But more detail is needed. So next in Section 3.1 I will take on this first task by bringing these various resources together, while also expanding on them in several ways. Second, we need an explanation of how such a HO theory-a theory born out of rejecting $\mathrm{M} 1$-does not change the subject away from phenomenal consciousness. That has not been discussed at all, and requires, amongst other things, a closer look at Nagelian 'what it is like'-talk. I'll provide that in Section 3.2. Only then can we show that such a HO theory counts as ambitious, and thus consider Farrell's challenge met.

\subsection{Phenomenal Consciousness without State Consciousness}

Let's begin by returning to the misrepresentation case. Here $S$ is in a higher-order representational state $M^{*}$. This state radically misrepresents: it represents $S$ as being in a firstorder state $M$ that she is not in. A supposition of the misrepresentation case is that there is something it is like for $S$ and because of this, $S$ is in a conscious state, at least in some sense of 'conscious state'. The claiming being made is this: $M^{*}$ is the conscious state.

This will no doubt strike many as a non-starter. We noted at the outset that HO theories are standardly introduced as implementations TRANSITIVITY. This works as quick and dirty way to get a grip on the theory. It's also fairly accurate, since there are $\mathrm{HO}$ theories that really do adhere to TRANSITIVITY as stated. Yet TRANSITIVITY, which says that conscious states are states we are aware of, strikes at the heart of the problem. Awareness is factive: if I am aware of $M, M$ exists. Since $M$ does not exist, by modus tollens I am not aware of $M$. So by TRANSITIVITY $M$ isn't conscious. But $M^{*}$ won't be conscious either, since it is assumed that we are not aware of $M^{*}$-we are not introspecting. $M^{*}$ is just the state that makes me aware of $M$, when I am aware of $M$. And I can be aware of $M$ without being aware of the state in virtue of which I am aware of $M$.

Consequently, the present story requires that the ambitious $\mathrm{HO}$ theorist dispense with TRANSITIVITY. This does not mean that we are no longer dealing with a HO theory, however. When HO theorists point to TRANSITIVITY, what they are doing is expressing a highly intuitive pretheoretic datum - a starting point for theorizing about consciousness. ${ }^{9}$ The core idea is that there is some interesting connection between being conscious - there being something it is like for a subject-and being aware of our mental states or being aware of ourselves as being in mental states. TRANSITIVITY Is just one way of expressing that core datum. And it does this by positing an awareness relation, one relata of which is a first-order mental state. For ease of comparison, we can rename TRANSITIVITY as:

${ }^{9}$ This sentiment is rife in the literature on HO theories. For some examples, see: Kriegel (2003: 106, 2009: 105); Lycan (as quoted by Gennaro 2011: 29); Lyyra (2009: 68); and Rosenthal (1997: 156, 2000: 273). 
State-Relational Transitivity A mental state $M$ of a subject is conscious only if that subject is in some way aware of $M$.

Farrell's first mistake is assuming that HO theorists are uniform in endorsing STATE-RELATIONAL TRANSITIVITY. They are not. ${ }^{10}$ Many ascribe to:

Self-Relational Transitivity A conscious state is a state whose subject is, in some way, aware of itself as being in that state.

HO theorists who endorse Self-ReLATIONAL TRANSITIVITY include Rosenthal (2011: 431), Weisberg (2011: 439), Berger (2011: 247), and Brown (2015: 1788). Unlike proponents of STATE-RELATIONAL TRANSITIVITY, proponents of SELF-RELATIONAL TRANSITIVITY get at this core datum by positing an awareness-as relation, where the relata is the self, which is then represented as being in some mental state. Yet SeLF-RELATIONAL TRANSITIVITY does not actually solve Farrell's challenge. This is because it still encourages the idea that the first-order state $\mathrm{M}$ is the conscious state; after all, it is this state that we are aware of ourselves as being in, and it is this state that we are not in during cases of radical misrepresentation. As Weisberg $(2011: 423, \mathrm{fn} .23)$ points out, on this form of HO theory, what is conscious is always an intentional object, an object that may or may not exist. This is the crux of the worry for Farrell, encapsulated by his claim that adopting a loose reading of WHAT simply changes the subject.

Now some who endorse SELF-ReLATIONAL TRANSITIVITY might not mean to say that $M$ is conscious in any sense beyond being an object of awareness, although that surely couldn't hold when one is not in $\mathrm{M}$, given that awareness is factive. In such a case the best we could do is say that we have a subjective impression of being in such a state. This is most obviously the case with Berger (2014). But then it is misleading for such HO theorists to endorse SELF-RELATIONAL TRANSITIVITY. They should instead endorse:

NeUtral TRANSitivity $S$ is in a (non-introspective, phenomenally) conscious state iff $S$ is aware of herself as being in some (first-order, representational) mental state.

Like Self-Relational Transitivity, Neutral Transitivity does away with relations between states. What you are aware of is yourself as being in some state. And awareness, while factive, is only weakly so. ${ }^{11}$ If I am aware of $x$, $x$ exists, but if I am aware of $x$ as being $F, x$ might not be $F$. S's $M^{*}$ renders $S$ aware of something that exists-viz. herself. It's just that such awareness is not factive with respect to the mental states $S$ is represented as being in.

Unlike Self-Relational TRANSITIVITY, however, NeUtRal TRANSITIVITY is explicitly neutral with respect to which state is the conscious state, in either sense of 'conscious state.' This allows the HO theorist to respect the core datum that motivates her theory without forcing her into a loose reading of WHAT-without, that is, seemingly forcing her to say that there is an occurrence of

${ }^{10} \mathrm{HO}$ theorists that do ascribe to STATE-ReLATIONAL TRANSITIVITY as stated include Kriegel (2009) and Gennarro (2011), both of whom ascribe to a self-representationalist form of HO theory.

${ }^{11}$ Berger (2014: 837) makes this basic distinction, albeit not with the same terminology. 
what-it-is-likeness associated with $\mathrm{M}$ even though $\mathrm{S}$ is not in $\mathrm{M}$. On NeUTRAL TRANSITIVITY it is still the case that being in a conscious state is related to our being aware of our mental states, and that higher-order representations are necessary for consciousness. For notice: first-order representations have exclusively first-order content. Such content is entirely world-directed, involving neither mental representations nor representational properties. If one thought that first-order representations were necessary and sufficient for consciousness, one would reject NEUTRAL TRANSITIVITY since, on it, S's $\mathrm{M}^{*}$ won't simply represent the world. It will represent $\mathrm{S}$ as being in a certain first-order state M. So the advocate of NEUTRAL TRANSITIVITY is decidedly a HO theorist.

With this point in place, along with our rejection of $\mathrm{M} 1$, what might an implementation of NEUTRAL TRANSITIVITY look like? There are a few ways one could go. But I will just set out one way. Since a subject's being in a conscious state presumably entails that the subject herself is conscious, the first move on the proposed HO theory is to reconfigure NEUTRAL TRANSITIVITY like this:

SUbJeCt-LeVel Transitivity $\quad \mathrm{S}$ is (non-introspectively) phenomenally conscious iff $\mathrm{S}$ is aware of herself as being in some (first-order, representational) mental state.

On SUBJECT-LeVEL TRANSITIVITY, $\mathrm{S}$ is phenomenally conscious in virtue of instantiating the right kind of $\mathrm{HO}$ representation $\mathrm{M}^{*}$ (Berger 2014; cf. Brown 2015). This representational state $M^{*}$ is 'the conscious state' of NeUTRAL TRANSITIVITY, but it is conscious only on The To-Be-In Model. All that is conscious on The Instantiation Model is $\mathrm{S}$ herself. By contrast, the first-order state $\mathrm{M}$ is not conscious on either model; it is not the state in virtue of which there is something it is like for $\mathrm{S}$, and it does not instantiate the property of being conscious. So on this HO theory, Farrell's M1 is false. ${ }^{12}$

Something like this view emerges upon close attention to the HO-theoretic landscape. A prevailing theme within some corners of that landscape is the idea that consciousness is a matter of mental appearance. The idea isn't metaphorical. Rosenthal and Weisberg put it this way:

Consciousness is a matter of mental appearance, that is, of how our mental states appear to us. And on higher-order theories, that mental appearance is due solely to the higher-order awareness. (2008: 4407)

The higher-order awareness Rosenthal and Weisberg speak of is a function of $\mathrm{M}^{*}$-for them, a assertoric HOT. It is $M^{*}$ that delivers the mental appearances by describing $M$ in qualitative

\footnotetext{
12 It's not clear what Farrell means by ' $M$ is conscious' in $M 1$. We noted that the natural reading is the reading in accordance with the Instantiation Model: to say that $M$ is conscious is to say that $M$ instantiates the property of being conscious. While Farrell never explicitly says he means anything otherwise, he (p. 9, fn. 24) does say that a tight reading of WHAT in M4 does not require that what-itis-like-ness be a property $M$. Then again, it's also not obvious that saying that is equivalent to saying that consciousness is not instantiated by $\mathrm{M}$. In any event, whatever Farrell means by ' $\mathrm{M}$ is conscious' in M1, M1 is false. That's because it is false on The To-Be-In reading too.
} 
terms. And mental appearances, like all appearances, can diverge from reality. ${ }^{13}$ That's what happens in misrepresentation, both radical or otherwise. We represent ourselves (via $\mathrm{M}^{*}$ ) as being in a mental state we are not in (in the radical case), or we falsely attribute a property to a mental state we are in (in the less radical case). So on this variant of HO theory, M plays no constitutive role in determining what it is like for a subject, even if it usually plays a causal role. That job goes to $M^{*}$. If we want to know what $M$ does do, we could supply the standard Rosenthalian (2010) answer: M plays a role in S's ability to discriminate amongst perceptible properties, relative to M's location within the space of other first-order sensory states. But that $M$ does this in no way depends on M's being conscious in either sense. ${ }^{14}$

The mental appearance view has its virtues, but the fan of SUBJECT-LEVEL TRANSITIVITY need not take on board all of its commitments. A few potential points of divergence might be particularly welcome. The proponent of SUBJECT-LEVEL TRANSITIVITY will need to offer identity conditions for subject-level phenomenal consciousness. A natural proposal is this: a subject $\mathrm{S}$ instantiates the phenomenal property $\mathrm{Q}-\mathrm{a}$ determinate of the determinable property phenomenal consciousness - as opposed to $Q^{\prime}$, iff $S$ instantiates $M^{*}{ }_{1}$ as opposed to $M^{*}{ }_{2}$. We can distinguish between $M^{*}{ }_{1}$ and $M^{*}{ }_{2}$ by their contents. An $M^{*}$ will always have a content of this form: [S, $M$, $x, F]$. Here ' $S$ ' picks out the subject who is in $M^{*}$, ' $M$ ' picks out the first-order perceptual state (a state of seeing, hearing, etc.), ' $x$ ' picks out the object, and ' $F$ ' picks out some perceptible property (e.g. redness). So here, unlike the mental appearance view, $M^{*}$ does not describe $M$ itself in qualitative terms, but in terms of the objects and properties it represents. A potential upshot of this shift is that the $\mathrm{HO}$ theorist can retain a benefit typically enjoyed by rival first-order theories: we let the F's-ordinary perceptible properties of external objects, if anything-serve as phenomenal qualities that are simply represented in experience (Tye 2014). That, in turn, can help the $\mathrm{HO}$ theorist avoid conflict with at one least variant of the transparency of experience thesis-roughly, the idea that the phenomenal qualities we are aware of in experience are all properties of external objects. ${ }^{15}$

Another potential point of divergence concerns the nature of $\mathrm{M}^{*}$. Rosenthal and Weisberg's mental appearance view claims that $\mathrm{M}^{*}$ is a HOT. That's a problem in the present context if only because it encourages one to wonder how a mere HOT-a species of ordinary thought-could possibly account for the richness, fineness-of-grain, and direct sense of phenomenal presence

13 To be fair, this has been denied-see, e.g. Kripke (1980). But it's not typically denied by HO theorists.

${ }^{14}$ This is not to deny that there will be cases where there is something it is like for S to be in $\mathrm{M}-$ viz. those cases where $\mathrm{S}$ is in $\mathrm{M}$, and $\mathrm{S}$ harbors the right kind of $\mathrm{M}^{*}$. But that will have nothing to do with $M$ itself, as what it is like for $S$ will be dictated by the content of $\mathrm{M}^{*}$. It won't be, in other words, in virtue of being in $\mathrm{M}$ that there is something it is like for $\mathrm{S}$ to be in $\mathrm{M}$. There is something it is like for $S$ to be in a state of having a normal blood coagulant level, but that state plausibly plays no role in what it is like experientially for $\mathrm{S}$.

${ }^{15}$ Rosenthal (2005: 120-121) comes quite close to expressly rejecting this construal of transparency. Given its widespread acceptance, I take it to be a virtue of the present HO theory that it can accommodate it. Of course, the present proposal wouldn't totally allay concerns about transparency for the HO theorist, given various ways that thesis is formulated. For discussion, see Gottlieb (2016). 
we associate with conscious experience (Gottlieb 2015; cf. Picciuto 2017). Without any appeal to rich, fine-grained first-order perceptual contents to carry the phenomenological burden, it's not obvious how this could work. After all, the way in which I am aware of (say) the Eiffel Tower when I think about it is vastly different from the way I am aware of it when I have a perceptual experience. One way out is just to claim that $\mathrm{M}^{*}$ is perception-like. That would render the present theory a variant of HOP, although quite different from how that view has been developed by Lycan. No doubt such a move requires further defense. HOTs themselves are uncontroversial. HOPs, by contrast, are. Still, the basic point is just this: rejecting M1 and adopting SUBJECT-LEVEL TRANSITIVITY opens a wide vista of options for the HO theorist that are ripe for exploration.

How plausible is this $\mathrm{HO}$ theory? I submit that it is not obviously less plausible than any more familiar standard HO theory. In fact, if-as I'll contend next-it meets the misrepresentation challenge without changing the subject, then we have an immediate reason to favor the present $\mathrm{HO}$ theory over other, more traditional, $\mathrm{HO}$ theories. It also can recover the intuition, had by many, that consciousness in an intrinsic non-relational property (Brown 2015: 1791). That can't be done on traditional $\mathrm{HO}$ theories that posits a relation between a first-order and higher-order mental state.

There is another somewhat related benefit. Kriegel (2009: 131) complains that HO theorists that treat radical misrepresentation by positing SELF-RELATIONAL TRANSITIVITY in lieu of STATE-RELATIONAL TRANSITIVITY violate the 'obvious truism' that there's something it's like for a subject only if she is in a conscious mental state, since on that view the first-order state $M$ is always conscious, even if one is not in it. Insofar as one take this to be an obvious truism, the present view does not violate it, since on that view it is true that that there's something it's like for a subject only if she is in a conscious mental state. It's just that the state is $\mathrm{M}^{*}$, and it's being conscious is not a matter of it instantiating the property of being conscious. Certainly the latter point violates no 'obvious truism.' If anything is a truism, it's that we instantiate the property of being consciousness.

That said, I don't want to say that denying that first-order states are conscious (in either sense) is perfectly intuitive (cf. Brown 2015: 1787). It might strike some as counterintuitive to deny, for instance, that my state of seeing a sunset is, or can be, conscious. But much of this unease can be dispelled. The present theory has it that whenever we are in a suitable $M^{*}$, we represent ourselves as being in some first-order state $M$. That first-order state is the state we seem to subjectively be in-a state of seeing a sunset, a pain state, etc. And in almost all cases we actually are in that state. (After all, most cases are likely not misrepresentation cases.) But it is because that state is the one we seem to subjectively be-whether we are in it or not-that we call it a 'conscious state.' We are not actually aware of $\mathrm{M}^{*}$, at least in normal cases. So this incarnation of $\mathrm{HO}$ theory actually predicts our tendency to think that it is our first-order states that are conscious. And maybe that's a legitimate use of 'conscious state.' Yet we should not infer from this that we can tell that it is actually $M$ that instantiates the property of being conscious, or that it is actually in virtue of $M$ that there is something it is like. That's not something we should obviously expect subjective appearances to reveal.

Any such oddness aside, there is also some evidence for phenomenal consciousness in the 
absence of first-order representations like M. Rosenthal often mentions the case of 'dental fear', where despite having her tooth anesthetized, or the relevant nerves being entirely absent, upon drilling, the dental patient reports being in pain. The precise details of how this works is unclear (e.g. Rosenthal 2005: 211). Still, it's not unreasonable to think that the patient is simply misrepresenting herself as being in pain. When what is really going on is explained to the patient, only awareness of the drilling remains. But as Rosenthal (2011: 436) notes, they still remember their prior experience as pain.

Another perhaps more controversial case comes from Rare Charles Bonnet Syndrome, where subjects report having vivid conscious visual experiences despite severe damage to primary visual cortex - the area of the brain where first-order visual representations are realized. Lau and Brown (2019) point out that, while one might reject the subjects' reports, this is ultimately untenable; these subjects are otherwise cognitively intact, and their reports are contemporaneous with the purported experiences, limiting the possibility of confabulation. ${ }^{16}$

Of course, all of this is for naught if this form of HO theory does change the subject. So let's examine that now.

\subsection{Nagel and the Nagelians}

'What it is like'-talk is slippery. It's not always clear that HO theorists and their opponents are using it in the same way. And HO theorists know this. For example, Weisberg (2011: 438-439) distinguishes between moderate and zealous uses of 'what it is like'-talk. The latter, but not the former, presumes that what-it's-like-ness is a monadic property of conscious states. HO theorists are thus (largely) committed to rejecting the zealous use, and it is only on the zealous usage that the misrepresentation argument has any bite.

Farrell realizes this too, at least implicitly; after all, as we saw, he thinks that HO theorists must adopt an occurrent reading of SOMETHING because, on HO theories, consciousness is not a monadic, or intrinsic, property of mental states. Regardless, pointing out, as Weisberg does, that $\mathrm{HO}$ theorists favor the modest usage over the zealous does not in itself resolve Farrell's challenge. Indeed, there is a sense in which doing so simply states the very impetus for the question at hand. In other words, doing so occasions this question: by rejecting the zealous usage, but also explicitly denying that consciousness is a property of states, does the HO theorist change the subject away from phenomenal consciousness? And we can answer that question only by looking at how Nagelian 'what it's like'-talk is introduced and used.

Specifically, the change-of-subject issue turns on three questions:

Q1 Does the current HO theory entail a loose reading of WHAT?

Q2 Does the current HO theory entail an occurrent reading of SOMETHING?

${ }^{16}$ For a reply to Lau and Brown, see Block (2019). For doubts that Rare Charles Bonnet Syndrome involves misrepresentation at all, see Kirkeby-Hinrup (2014). 
Q3 Is the standard conception of phenomenal consciousness one on which it is fundamentally a property of mental states (be it a monadic or relational property), contra the current $\mathrm{HO}$ theory?

If the answer to any of these questions is yes, then we are back to the same problem embodied in P7. The HO theorist will have 'responded' to the misrepresentation objection, but only at the expense of her ambitiousness. Fortunately for the present form of $\mathrm{HO}$ theory, the answer to each question is no.

On Q1: Farrell argued that HO theorists take a loose reading of WHAT, allowing them to say that there can be an occurrence of what-its-likeness that is 'associated' with M even though $\mathrm{S}$ is not in $\mathrm{M}$. We should now see why this is wrong. The occurrence of what-its-likeness, on the present $\mathrm{HO}$ theory, is actually associated with $\mathrm{M}^{*}$, a state which $\mathrm{S}$ is in: what $\mathrm{M}^{*}$ represents fixes what it is like for S. This state is the state in virtue of which there is something it is like for S. Therefore, the answer to Q1 is no.

On Q2: Farrell argued that $\mathrm{HO}$ theorists take a non-standard occurrent reading of SOMETHING. On a standard non-occurrent reading, all that is required is that when Mary experiences red, there is an occurrence of what-it-is-like-ness associated with experiencing red. It can be true that there is something it is like for Mary to see red' even in situations when there is no occurrence of whatit-is-like-ness associated with her experiencing red-as in the situation where she is still trapped in her black-and-white room. As we saw, Farrell claims (p. 7) that this reading was not open to a $\mathrm{HO}$ theorist because for them, consciousness is an extrinsic property of states. But this is a nonstarter if consciousness is not a property of states at all. It is true that when Mary instantiates an $\mathrm{M}^{*}$ that represents her as seeing something red, there will be something it is like for Mary to experience red. Therefore, the answer to Q2 is also no.

Before turning to Q3, it will be instructive to briefly compare the present take on Q1 and Q2 with how HO theorists have addressed these issues previously. To take just one case, consider Weisberg's approach. Weisberg (2011: 423, fn. 23) claims that HO theory is "committed to the claim that a nonexistent state can have a property, the property of being conscious." This suggests two things of note. First, Weisberg seems to accept The Instantiation Model. The present theory rejects it. Second, he contends that it is the first-order state $M$ that instantiates the property of being conscious, even if only a relational one. The present theory denies this too. Both points encourage Farrell to read Weisberg as answering 'yes' to Q1 and Q2. Whether or not that's the right way to read Weisberg, the theory on offer encourages no such thing.

Finally, on Q3: to say that consciousness is a property of mental states is not, of course, to deny that consciousness is also a property of subjects. We can say that subjects are conscious in virtue of being in mental states that have the property of being conscious. This would make consciousness fundamentally a property of mental states, and derivatively a property of subjects. So does denying this cut against the standard conception?

Naturally, that depends on what fixes the standard conception. According to Farrell, the standard 
sense is by and large the Nagelian sense-it is "that notion of consciousness which Nagel suggests makes the mind-body problem intractable" (p. 17). The claim here is not that Nagel has any special authority in fixing our explanatory target (p. 15). Rather, it's only that the popularity of appealing to 'what it is like'-talk in discussions of consciousness in the years following Nagel's paper shows that many philosophers, including proponents of the misrepresentation argument, understand consciousness in roughly the way Nagel did.

Now if you look at what Nagel actually says, it's not at all clear that the answer to Q3 is yes. Substituting 'subject' for 'organism' and 'conscious state' for 'conscious experience,' here is how Nagel put things:

NAgel's Nagel A subject has conscious states if and only if there is something it is like to be that subject (1974: 436).

Compare this with Farrell's formulation:

Farrell's Nagel A mental state is conscious if and only if there is something it is like for $S$ to be in that mental state (p. 2).

NAGEL'S NAGEL is a claim about what it is for a subject to have conscious states. FARRELL'S NAGEL is a claim about what it is for a state to be conscious. So FARRELL'S NAGEL is not NAGEL'S NAGEL.

The present HO theory can be seen as a way of filling out NAGEL'S NAGEL. A subject has conscious states if and only if there is something it is like to be that subject. On this HO theory, for a subject to have a conscious state is for the subject to instantiate the right kind of higher-order representation, $\mathrm{M}^{*}$. That higher-order representation is a 'conscious state' in the sense that it is in virtue of being in that state that there is something it is like to be $S$. Thus, it is true that S's having a conscious state entails that $S$ is in a conscious state. But this does not mean that the 'conscious state'-the higher-order representation-S is in instantiates the property of being conscious. For that just assumes the Instantiation Model, which is something (this form of) ambitious $\mathrm{HO}$ theorist rejects for phenomenal consciousness, and something that ought not be built into NAGEL'S NAGEL. The only thing that instantiates the property of being phenomenally conscious is S. And S's being phenomenal conscious just is $S$ instantiating the right kind of higherorder representation.

Farrell will probably deny that FARRELL'S NAGEL is an interpretation of Nagel. Instead it is Farrell's explication of (what we might think of as) our 'Nagelian Heritage': it is what many people who take themselves to be talking about the same phenomenon as Nagel endorse. This is critical. For sake of argument, let's take the 'is conscious' in FARRELL'S NAGEL literally, and construe it in terms of the Instantiation Model so that 'is conscious' is read as 'instantiates the property of being conscious.' Then we can read the worry like this: those who reject HO theory press the misrepresentation argument against a shared interpretive backdrop for 'what it is like'-talk. Constituting this backdrop is not just a claim about SOMETHING (viz. that its standard reading is a non-occurrent reading), and a claim about WHAT (viz. that its standard reading is a tight reading), 
but also that consciousness is a property of (first-order) states. HO theorists are no doubt free to decide what their theory is a theory of, but to 'respond' to the misrepresentation argument by deviating from this backdrop-in particular by denying that consciousness is a property of states-is to admit that one aims only to account for consciousness on a special HO reading.

There are two points to be made here. First, it's doubtful that there is such a shared interpretive backdrop. For instance, Jeff Speaks (2015) rejects HO theory. Yet he also says (2014: 82) that consciousness is fundamentally a property of subjects, and that ditching talk of 'conscious states' and 'conscious experience' entails no loss of expressive power.

Alex Byrne (1997) also rejects HO theory, and precisely due to concerns about misrepresentation. Yet he too would be skeptical of M1, saying that 'experience' in the relevant philosophical sense is "far from an innocent count noun." 17 Byrne actually goes further, and denies that there are experiences. To deny that there are experiences in the relevant sense is to deny that there are experiences qua mental particulars, specifically particular mental events; it is not to deny that there are experiences in the everyday biographical sense. It is still true that watching the NY Yankees get knocked out of the MLB playoffs was an unpleasant one, while eating at Chez Panisse was anything but. But as Byrne notes, inferring 'from this that there are 'visual experiences' and 'gustatory experiences' in the special philosophical sense is just to ignore the fact that 'experience' in its philosophical use is not a harmless extension of ordinary usage" (2009: 433). So if experiences themselves are in doubt by opponents of $\mathrm{HO}$ theory, denying that consciousness is a property of experience can hardly be tantamount to changing the subject. It's precisely the opposite. $^{18}$

Second, it is wrong-headed to think that because proponents of the misrepresentation argument assume that consciousness is a property of states, any response to the argument that proceeds by rejecting that assumption is somehow changing the subject in any problematic sense. We should strive to get a fix on our phenomenon of interest by employing theory-neutral descriptions. The phenomenon of interest is phenomenal consciousness. This is the property we associate with smelling sautéed garlic or the throbbing pain that occurs when one stubs their toe. It is the property that, following Nagel, we introduce with 'what it is like'-talk. These are

17 See Byrne (2009: 433), channeling Charles Travis (2004: 57). For further similar doubts about attributing consciousness to experiences and mental states, see Tye (2003) and Nida-Rumelin (2016). 18 If we say that experiences are events, and M1 concerns (first-order) conscious states, is Byrne's skepticism about experiences still relevant? Yes. While states are sometimes contrasted with events, as Byrne (2009: 432) himself points out, in the philosophy of mind 'state' is often used as a convenient catchall term, with 'mental state' meaning "mental condition, event, phenomenon, or whatever." HO theorists are no exception to this, often using 'conscious experience' interchangeably with 'conscious state' (see, e.g. Carruthers 2000, Rosenthal 2005). And for those who insist on being extra persnickety, Jaegwon Kim's (1991) property-exemplification theory is useful. If being in a state just is instantiating a property, then S's undergoing a conscious experience is matter of $\mathrm{S}$ instantiating the right sort of property at a time $t$. 
ostensibly theory-neutral descriptions. ${ }^{19}$ But to build in, from the get-go, that this property is actually instantiated by my (say) olfactory state, is to inflate our concept of phenomenal consciousness with a highly theoretical claim. It is no doubt true that we ascribe to ourselves what looks like first-order conscious states. If Mary runs by me at top speed with a look of abject fear on her face, I might explain why by saying that she saw a bear. In doing so I ascribe to her a conscious first-order state---a state of consciously seeing the bear. The HO theorist who denies M1 will not want to say that these attributions are unjustified. The point though is that she doesn't have to. Again, to say, truthfully, that Mary is in a first-order conscious state need not be a matter a matter of saying - falsely, if this type of $\mathrm{HO}$ theorist is right-that she is in a first-order state that instantiates the property of being conscious (extrinsic or otherwise), or that what it is like for her is a function of a first-order state. It can just be that she has a suitable subjective appearance of seeing a bear, a subjective appearance is supplied by $M^{*}$. Calling the state Mary subjectively appears to be in-and will be in, if she actually sees a bear-a 'conscious state' is fine. We should just not take this as implying that that state is conscious on either the To-Be-In or Instantiation Models.

Finally, even the very 'what it is like'-talk that we use to introduce phenomenal consciousness, and the 'what it is like'-sentences that talk involves, seems, if anything, to point towards the claim that phenomenal consciousness is fundamentally a property of subjects. When we say that there is something that it is like' in the relevant sense, this is always a claim about what it is like for $a$ subject. ${ }^{20}$ If I ask what was it is like for you to stub your toe, you invariably point to properties you instantiate-the way you feel etc.

All of this suggests an answer of 'no' to Q3. But if that's right, given the 'no' answers to Q1 and Q2, the present $\mathrm{HO}$ theorist does not change the subject. She is not simply explaining phenomenal consciousness in the $\mathrm{HO}$ sense. She can genuinely respond to the misrepresentation argument. She can, in other words, respond to the misrepresentation argument without abandoning her ambitions.

\section{Conclusion}

Misrepresentation objections to HO theories are not new. Farrell's, however, is novel. It is novel because it turns on semantic and conceptual matters, in particular how we understand key

\footnotetext{
${ }^{19}$ Remember: the current $\mathrm{HO}$ theorist can fully grant that phenomenal consciousness is associated in some loose sense with these states; almost all of the time, my smelling sautéed garlic will be accompanied by a suitable $\mathrm{M}^{*}$. And even when there is an $\mathrm{M}^{*}$ without any such lower-order state (as in radical misrepresentation cases), it is a tenet of the theory that it will still seem as if I am in that lower-order state. This is because it is virtue of $\mathrm{M}^{*}$ that I have a suitable subjective impression that I am smelling sautéed garlic.

${ }^{20} \mathrm{Cf}$. Brown (2015: 1789). Stoljar (2016: 6) points out that it is part of the logical structure of 'what it is like'-sentences that they always include a covert subject, viz. a prepositional phrase of the form 'for $S$,' where ' $S$ ' refers to the subject that it conscious.
} 
components of 'what it is like'-talk like SOMETHING and WHAT. This allows Farrell to charge the HO theorist not with internal inconsistency (like Block) but with a dodge: what the misrepresentation objection shows, at bottom, is that HO theorist understands 'phenomenal consciousness' in a non-standard, deviant manner. There are no ambitious HO theories-no HO theories of phenomenal consciousness-even if there are $\mathrm{HO}$ theories of other types of consciousness.

I have argued that this is false. Farrell's misstep had two components. First: he is mistaken about the scope of possibilities within the HO-theoretic framework. The HO theorist can reject M1 and allow that $\mathrm{M}^{*}$ is conscious, at least on the To-Be-In Model. Second: he is mistaken about what is, and what is not, an account of phenomenal consciousness, and so by extension, when a HO theory deserves the appellation of 'ambitious.' Taking a cue from Berger (2014) and Brown (2015), I have articulated one way such a HO theory could work. The result is a view perfectly in line with standard usages of SOMETHING, WHAT and anything else we might say about 'what it is like'-talk. Such a $\mathrm{HO}$ theory might be the wrong account of phenomenal consciousness, but it is an account of phenomenal consciousness in the standard sense. Thus, insofar as the misrepresentation objection goes, ambitious $\mathrm{HO}$ theories can, I think, live to see another day. ${ }^{21}$

\section{References}

Armstrong, D. (1968). A Materialist Theory of Mind. Routledge.

Berger, J. (2014). Consciousness is Not a Property of States: A Reply to Wilberg. Philosophical Psychology, 27 (6): 829 - 842.

Block, N. (2011). The higher-order approach to consciousness is defunct. Analysis, 71 (3): 419431.

Block, N. (2019). Empirical Science meets Higher-Order Views of Consciousness: Reply to Lau and Brown. In Adam Pautz \& Daniel Stoljar (eds.), Blockheads! Essays on Ned Block's Philosophy of Mind and Consciousness. MIT Press.

Brown, R. (2014). Review of "The Consciousness Paradox: Consciousness, Concepts, and HigherOrder Thoughts" by Rocco Gennaro. http://ndpr.nd.edu/news/the-consciousness-paradoxconsciousnessconcepts-and-higher-order-thoughts/.

Brown, R. (2015). The HOROR Theory of Consciousness. Philosophical Studies, 172 (7), 17831794.

Byrne, A. (1997). Some Like It HOT: Consciousness and Higher-Order Thoughts. Philosophical Studies, 86(2), pp. 103-29.

Byrne, A. (2009). Experience and Content. The Philosophical Quarterly, 59 (236): 429-451.

Carruthers, P. (2000). Phenomenal Consciousness: A Naturalistic Theory. Cambridge: Cambridge University Press.

Farrell, J. (2016). 'What it is Like Talk is not Technical Talk. Journal of Consciousness Studies, 23 (9-10): 50-65.

\footnotetext{
${ }^{21}$ For very helpful comments and discussion, I thank Jonathan Farrell and two anonymous referees for Philosophical Psychology.
} 
Farrell, J. (2017). Higher-order theories of consciousness and what-it-is-like-ness. Forthcoming in Philosophical Studies. Online first: DOI 10.1007/s11098-017-0980-8.

Hellie, B. (2007). Higher-Order Intentionalism and Higher-Order Acquaintance. Philosophical Studies, 134 (3): 289-324.

Gennaro, R. (2011). The Consciousness Paradox: Consciousness, Concepts, and Higher-Order Thoughts. Cambridge, MA: MIT Press.

Gottlieb, J. (2015). Presentational Character and Higher-Order Thoughts. Journal of Consciousness Studies 22 (7-8):103-123

Gottlieb, J. (2016). Transitivity and Transparency. Analytic Philosophy 57 (4):353-379.

Gottlieb, J. (2018). Verbal Disputes in the Theory of Consciousness. Ergo: An Open Access Journal of Philosophy 5.

Kriegel, U. (2003). Intransitive Self-Consciousness: Two Views and an Argument. The Canadian Journal of Philosophy 33 (1): 103-132.

Kriegel, U. (2009). Subjective Consciousness: A Self-Representational Approach. Oxford: Oxford University Press.

Kirkeby-Hinrup, A. (2014). Why the Rare Charles Bonnet Cases Are Not Evidence of Misrepresentation. Journal of Philosophical Research 39 301-308.

Kripke, S. (1980). Naming and necessity. Cambridge, MA: Harvard University Press.

Kim, J. (1991). Events: Their metaphysics and semantics. Philosophy and Phenomenological Research. 51(3), 641-646.

Lau, H. \& Richard Brown. (2019). The Emperor's New Phenomenology? The Empirical Case for Conscious Experience without First-Order Representations. In Adam Pautz \& Daniel Stoljar (eds.), Blockheads! Essays on Ned Block's Philosophy of Mind and Consciousness. MIT Press.

Levine, J. (2001). Purple Haze. Oxford: Oxford University Press.

Lycan, W. (1996). Consciousness and Experience. Cambridge, MA: MIT Press.

Lyyra, P. (2009). Two senses for givenness of consciousness.' Phenomenology and Cognitive Science 8: 67-87.

Mandik, P. (2009). Beware of the unicorn: Consciousness as being represented and other things that don't exist. Journal of Consciousness Studies, 16(1), 536.

Nagel, T. (1974). What is it like to be a bat? Philosophical Review, 83: 435- 450.

Picciuto, V. (2017). Keeping it Real: Intentional Inexistents, Fineness-of-Grain, and the Dilemma for Extrinsic Higher-Order Representational Theories. Pacific Philosophical Quarterly 98 (4):555-575.

Neander, K. (1998). The division of phenomenal labor: A problem for representationalist theories of consciousness. Philosophical Perspectives, 12, 411-434.

Rosenthal, D.M. (1997). A Theory of Consciousness. In Ned Block, Owen J. Flanagan \& Guven Guzeldere (eds.), The Nature of Consciousness. Cambridge, MA: MIT Press.

Rosenthal, D.M. (2000). Consciousness and Metacognition. In Dan Sperber (ed.), Metarepresentation. Oxford: Oxford University Press.

Rosenthal, D. M. (2005). Consciousness and Mind. Oxford: Clarendon Press.

Rosenthal, D. M. (2005). How to Think about Mental Qualities. Philosophical Issues 20 (1): 368393.

Rosenthal, D.M. (2011). Exaggerated Reports: A Reply to Block. Analysis, 71 (3): 431-437.

Rosenthal, D.M., and Josh Weisberg (2008). Higher-order theories of consciousness. 
Scholarpedia, 3(5): 4407.

Nida-Rumelin, M. (2016). The experience property frame work: a misleading paradigm. Synthese. Online first: DOI 10.1007/s11229-016-1121-1.

Speaks, J. (2014). What Are Debates About Qualia Really About? Philosophical Studies. 170 (1): 1-26.

Speaks, J. (2015). The Phenomenal and The Representational. Oxford: Oxford University Press.

Stoljar, D. 2016. 'The Semantics of 'What it is like'-sentences and The Nature of Consciousness'. Mind. Online first: DOI 10.1093/mind/fzv179.

Travis, C. (2004). The Silence of the Senses. Mind. 113 (449): 57-94.

Tye, M. (2003). Consciousness and Persons: Unity and Identity. Cambridge, MA: MIT Press.

Tye, M. (2014). Transparency, qualia realism and representationalism. Philosophical Studies 170 (1):39-57

Weisberg, J. (2008). Same Old, Same Old: The Same-Order Representational

Theory of Consciousness and the Division of Phenomenal Labor. Synthese 160 (2): 161-181.

Weisberg, J. (2011). Mispresenting Consciousness. Philosophical Studies 154 (3): $409-433$.

Weisberg, J. (2011). Abusing the notion of what-it's-like-ness: A response to Block. Analysis, 71 (3), 443448.

Wilberg, J. (2010). Consciousness and False HOTs. Philosophical Psychology, 23 (5):617-638. 